\title{
Anti-adipogenic effects of extracts of Ficus deltoidea var. deltoidea and var. angustifolia on 3T3-L1 adipocytes"
}

\author{
Shiau Mei WOON ${ }^{1}$, Yew Wei SENG ${ }^{1}$, Anna Pick Kiong LING $^{\dagger+2}$, Soi Moi CHYE ${ }^{2}$, Rhun Yian $\mathrm{KOH}^{2}$ \\ ( ${ }^{I}$ School of Pharmacy, International Medical University, Bukit Jalil, 57000 Kuala Lumpur, Malaysia) \\ ( ${ }^{2}$ Department of Human Biology, International Medical University, Bukit Jalil, 57000 Kuala Lumpur, Malaysia) \\ †E-mail: anna_ling@imu.edu.my \\ Received Apr. 25, 2013; Revision accepted Oct. 14, 2013; Crosschecked Feb. 21, 2014
}

\begin{abstract}
Objective: This study examined the anti-adipogenic effects of extracts of Ficus deltoidea var. deltoidia and var. angustifolia, a natural slimming aid, on 3T3-L1 adipocytes. Methods: Methanol and water extracts of leaves of the F. deltoidea varieties were analyzed to determine their total flavonoid content (TFC) and total phenolic content (TPC), respectively. The study was initiated by determining the maximum non-toxic dose (MNTD) of the methanol and water extracts for 3T3-L1 preadipocytes. Possible anti-adipogenic effects were then examined by treating 2-d post confluent 3T3-L1 preadipocytes with either methanol extract or water extract at MNTD and half MNTD (1/2MNTD), after which the preadipocytces were induced to form mature adipocytes. Visualisation and quantification of lipid content in mature adipocytes were carried out through oil red $O$ staining and measurement of optical density (OD) at $520 \mathrm{~nm}$, respectively. Results: The TFCs of the methanol extracts were 1.36 and $1.97 \mathrm{~g}$ quercetin equivalents (QE)/100 $\mathrm{g}$ dry weight (DW), while the TPCs of the water extracts were 5.61 and $2.73 \mathrm{~g}$ gallic acid equivalents (GAE)/100 $\mathrm{g}$ DW for var. deltoidea and var. angustilofia, respectively. The MNTDs determined for methanol and water extracts were $(300.0 \pm 28.3)$ and $(225.0 \pm 21.2) \mu \mathrm{g} / \mathrm{ml}$, respectively, for var. deltoidea, while much lower MNTDs [(60.0 \pm 2.0$) \mu \mathrm{g} / \mathrm{ml}$ for methanol extracts and $(8.0 \pm 1.0) \mathrm{\mu g} / \mathrm{ml}$ for water extracts] were recorded for var. angustifolia. Studies revealed that the methanol extracts of both varieties and the water extracts of var. angustifolia at either MNTD or $1 / 2$ MNTD significantly inhibited the maturation of preadipocytes. Conclusions: The inhibition of the formation of mature adipocytes indicated that leaf extracts of $F$. deltoidea could have potential anti-obesity effects.
\end{abstract}

Key words: Adipogenesis, Ficus deltoidea, Flavonoids, Natural products, Obesity doi:10.1631/jzus.B1300123 Document code: A CLC number: R285

\section{Introduction}

Obesity has become a major concern among people of all ages in both developed and developing nations. Despite the never-ending global awareness campaign, the obesity rate is still on the rise globally, leading to complications like cardiovascular diseases, diabetes, musculoskeletal disorders, and some can-

\footnotetext{
${ }^{\ddagger}$ Corresponding author

* Project supported by the International Medical University (No. BPharm B0108_Res072011), Malaysia

(C) Zhejiang University and Springer-Verlag Berlin Heidelberg 2014
}

cers (Moon et al., 2007). There are many ways to treat obesity. However, multiple interventions are required for successful treatment, such as regular exercise, proper diet and food energy intake, and behavioural modification, as well as pharmacotherapy that involves the administration of slimming pills. Slimming pills such as Orlistat, a lipase inhibitor, prevent the absorption of fats by the intestines. These unabsorbed fats are then removed from the body, causing undesirable side effects such as oily stool, loose stool, and irregular menstrual periods (Padwal and Majumdar, 2007). Hence, alternatives such as the application of natural products should be sought for anti-obesity 
therapy. One example of a natural product is Citrus aurantium, which is able to increase the metabolic rate and fat loss in obese subjects without showing adverse side effects (Preuss et al., 2002). Recently, among Malaysian communities, Ficus deltoidea has also been used as a raw material for slimming pills.

$F$. deltoidea belongs to the Moraceae family and is native to Southeast Asia, including Malaysia, Indonesia, and the Philippines (Aris et al., 2009). It is cultivated as a houseplant or as an ornamental shrub. It is traditionally used in herbal remedies to treat hypertension, diabetes, headache, and fever, and to reduce the risk of cancer. It is also used in postpartum treatment (Ilyanie et al., 2010). Its tea has also been sold as a slimming aid. Despite all these traditional claims, scientific studies of this plant are very limited, and most have focused on evaluating its anti-oxidant (Abdullah et al., 2011), anti-hyperglycemic (Ilyanie et al., 2010; Adam et al., 2011), anti-nociceptive, anti-hypertensive, wound, and ulcer healing (Abdullah N.A.H. et al., 2008; Sulaiman et al., 2008; Zahra et al., 2009; Abdullah M.A. 2010; Adam et al., 2011) properties. There have been no reports regarding anti-adipogenesis effects of $F$. deltoidea that can validate its application as a slimming aid. One of the flavonoids, quercetin, presented in significant amounts in $F$. deltoidea (Ong et al., 2010) has been reported to be able to attenuate adipogenesis by activating the adenosine monophospate-activated protein kinase pathway and decreasing the expression of adipogenesis-related factors and enzymes in 3T3-L1 preadipocytes (Ahn et al., 2008). Hence, this study was conducted to assess the anti-adipogenic properties of water and methanol extracts derived from leaves of two varieties of $F$. deltoidea, namely var. deltoidea and var. angustifolia.

\section{Materials and methods}

\subsection{Preparation of plant materials}

The two varieties of $F$. deltoidea were collected from Sungai Buloh, Malaysia. Their botanical identities were determined and authenticated by a taxonomist. The leaves, which have been widely used as raw material of slimming pils, were then washed, cleaned, and air-dried at room temperature for a week.

\subsection{Preparation of plant extracts}

\subsubsection{Methanol extraction}

The dried leaves from the plants were ground to a fine powder, weighed, and extracted with methanol (Fisher, UK) at a ratio of $1 \mathrm{~g}$ to $10 \mathrm{ml}$. The extract then was soaked in the dark at room temperature for three days. The resulting suspension was filtered, and the filtrate was concentrated and dried using a rotary evaporator (Buchi, USA).

\subsubsection{Water extraction}

The dried leaves were ground to a fine powder, measured and extracted with hot water at $60{ }^{\circ} \mathrm{C}$ in a ratio of $1 \mathrm{~g}$ to $10 \mathrm{ml}$ for $3 \mathrm{~h}$. After filtration, the filtrate was kept at $-80^{\circ} \mathrm{C}$ overnight prior to freeze-drying.

\subsection{Characterisation of extracts}

\subsubsection{Total flavonoid content (TFC)}

Methanol extracts were characterised for TFC using the aluminium chloride colourimetric method (Chang et al., 2002). A total of $0.5 \mathrm{ml}$ of extract was mixed with $1.5 \mathrm{ml}$ of $95 \%$ methanol, $0.1 \mathrm{ml}$ of $10 \%$ aluminium chloride (Sigma-Aldrich, USA), $0.1 \mathrm{ml}$ of $1 \mathrm{~mol} / \mathrm{L}$ potassium acetate (Sigma-Aldrich, USA), and $2.8 \mathrm{ml}$ of distilled water. The mixture was incubated for $30 \mathrm{~min}$ at room temperature. The absorbance was then measured using a spectrophotometer (Shimadzu, Japan) at $415 \mathrm{~nm}$. The TFC was then expressed as grams of quercetin equivalents per $100 \mathrm{~g}$ dry weight (g QE/100 g DW) by comparison with a quercetin standard curve.

\subsubsection{Total phenolic content (TPC)}

Characterisation of water extracts was carried out based on their TPC measured using the FolinCiocalteau method (Lin and Tang, 2007). A total of $0.1 \mathrm{ml}$ of $0.1 \mathrm{~g}$ of lyophilised samples was mixed with $2.8 \mathrm{ml}$ of distilled water, $2 \mathrm{ml}$ of $2 \%$ sodium carbonate (Fisher, UK), and $0.1 \mathrm{ml}$ of $50 \%$ Folin-Ciocalteau reagent (Sigma-Aldrich, USA). Then, the mixture was incubated at room temperature for $30 \mathrm{~min}$, followed by measuring the absorbance at $750 \mathrm{~nm}$. The TPC was then expressed as grams of gallic acid equivalents per $100 \mathrm{~g}$ of lyophilised powder (g GAE/100 g DW) by comparing with a gallic acid standard curve. 


\subsection{T3-L1 cell culture and standard adipogenic induction protocols}

The 3T3-L1 mouse embryo fibroblasts were cultured in Dulbecco's modified Eagle's medium (DMEM) (Invitrogen, USA) containing 10\% bovine calf serum (Sigma-Aldrich, USA). Two days postconfluence, the medium was replaced with 3T3-L1 differentiating medium (Zenbio, USA). After two days, this medium was replaced with 3T3-L1 adipocyte medium (Zenbio, USA) and incubated for an additional two days. The cells were then cultured in adipocyte medium for another four days, by which time more than $90 \%$ of cells had differentiated into mature adipocytes. The cells were maintained at $37{ }^{\circ} \mathrm{C}$ in a humidified $5 \% \mathrm{CO}_{2}$ incubator (RS Biotech Galaxy S, UK).

\subsection{Characterization of adipogenesis}

The 3T3-L1 preadipocytes were plated in 24-well plates at a density of $0.2 \times 10^{5}$ cells/well and standard adipogenic induction protocols were followed. The differentiation of 3T3-L1 preadipocytes to mature adipocytes was confirmed by oil red $\mathrm{O}$ (ORO; Sigma-Aldrich, USA) staining.

\subsection{Determination of maximum non-toxic dose (MNTD) of the extracts on 3T3-L1 cells}

3T3-L1 preadipocytes were seeded in 96-well plates at the density of 5000 cells/well. At $70 \%$ confluency, the cells were treated with $150-300 \mu \mathrm{g} / \mathrm{ml}$ of water extracts or $200-400 \mu \mathrm{g} / \mathrm{ml}$ of methanol extracts for $48 \mathrm{~h}$. Cell viability was then measured using 3(4,5-dimethythizol-2-yl)-5-(3-carboxymethoxyphenyl)2-(4-sulfophenyl)-2H-tetrazolium salt solution (MTT; Biobasic, USA) assay. The methods involved adding $10 \mu \mathrm{l}$ of MTT solution to each well and incubation of the cells in the dark for $4 \mathrm{~h}$ at $37{ }^{\circ} \mathrm{C}$. The absorbance was then measured using a microplate reader (Tecan Infinite, Austria) at $570 \mathrm{~nm}$ to determine the formazan concentration. The percentages of cell viability and toxicity were then calculated. A graph of percentage of cytotoxicity against the concentration of extract was plotted to determine the MNTD and half MNTD $(1 / 2 \mathrm{MNTD})$ of the extracts.

\subsection{Cell treatments}

3T3-L1 cells were seeded in 96-well plates at a density of 5000 cells/well. On Day 2, the extract was added at the concentration of the MNTD or the $1 / 2$ MNTD. The cells were then subjected to the standard adipogenic induction protocols prior to adipogenic assay on Day 10.

\subsection{Determination of anti-adipogenic activity}

To visualise the lipid content, the treated cells were washed twice with phosphate buffered saline (PBS) (MP Biomedicals, France) and fixed with 10\% formalin (Friendemann Schmidt, Australia) in PBS at $\mathrm{pH}$ 7.4. Cells were then subjected to ORO staining. The images for each dish were then captured. To quantify the lipid content in mature adipocytes, the staining dye was eluted by adding 100\% isopropanol (Friendemann Schmidt, Australia) and the optical density (OD) was measured at $520 \mathrm{~nm}$ using 100\% isopropanol as a blank, as described by Hsu and Yen (2007).

\subsection{Statistical analysis}

The experiments were performed in triplicates and data are presented as mean \pm standard deviation (SD). One-way analysis of variance (ANOVA) was performed followed by post-hoc Tukey's honest significant difference (HSD) test using SPSS software, to determine significant differences $(P<0.05)$ between means.

\section{Results and discussion}

\subsection{Characterisation of extracts}

Phytochemical profiling studies on plants of $F$. deltoidea discovered that they contain secondary metabolites such as saponins, flavonoids, tannis, polyphenols, triterpenoids, and proanthrocyanins. In this study, the TFC of methanol extracts of $F$. deltoidea var. deltoidea was found to be $(1.36 \pm 0.05) \mathrm{g}$ $\mathrm{QE} / 100 \mathrm{~g}$ DW. The TPC in water extracts was $(5.61 \pm 0.48) \mathrm{g} \mathrm{GAE} / 100 \mathrm{~g}$ DW. In contrast, methanol extracts of $F$. deltoidea var. angustifolia recorded TFC of $1.97 \mathrm{~g} \mathrm{QE} / 100 \mathrm{~g}$ DW, while water extracts contained $2.73 \mathrm{~g}$ GAE/100 g DW. The values recorded in this study were found to be lower than the values of $5.15 \mathrm{~g} \mathrm{QE} / 100 \mathrm{~g}$ and $7.35 \mathrm{~g} \mathrm{GAE} / 100 \mathrm{~g}$, respectively, reported by Abdullah et al. (2011). This might be caused by the loss of constituents when the leaves were subjected to drying, grinding, and heating (Sukrasno et al., 2011). Alternatively, it has been 
shown that plants originating from different geographical locations may vary in their phytochemical profiles and compositions (Filippini et al., 2010).

\subsection{Characterization of adipogenesis}

3T3-L1 preadipocytes possess an extended fibroblast-like morphology. When treated with the differentiating medium containing isobutylmethylxanthine, dexamethasone and insulin (MDI), the cells successfully differentiated into mature adipocytes, which were round in shape and contained cytoplasmic lipid vesicles (Fig. 1). Intracellular lipid accumulation in the form of lipid droplets was confirmed by ORO staining. ORO is an azo dye, which is soluble in fats (lysochrome) (Guigui and Beaudoin, 2007). ORO contains one portion which dissolves in contact with fat and another which is responsible for its colour. Hence, ORO stains lipids by dissolving in them.

(a)

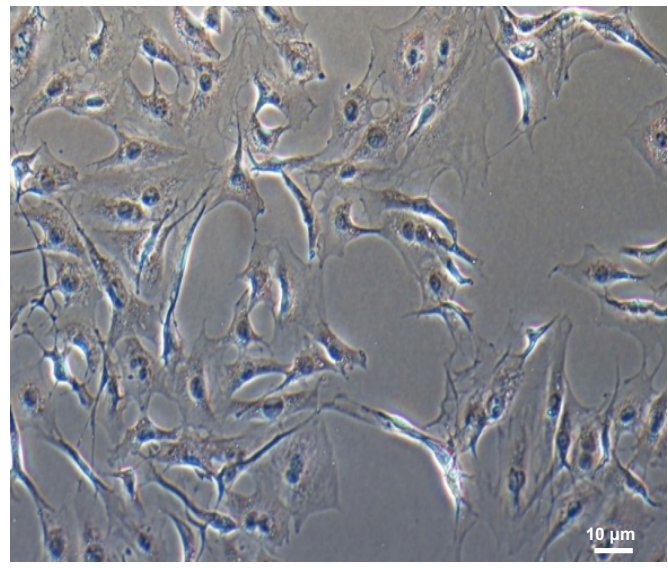

(b)

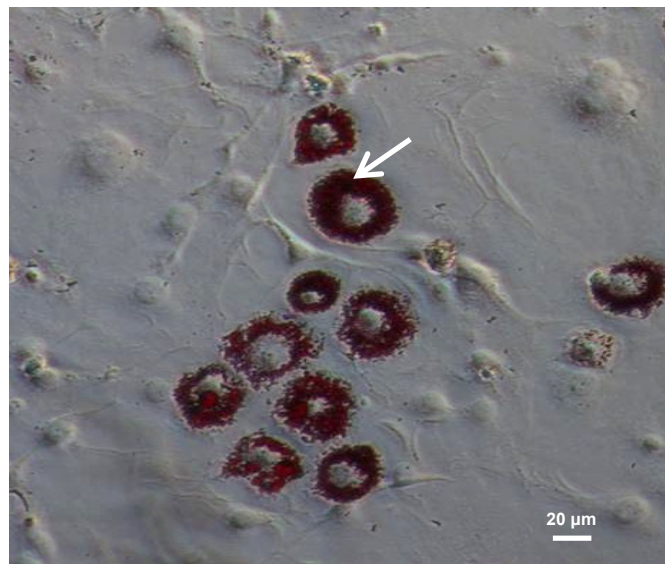

Fig. 1 Adipogenesis of 3T3-L1 preadipocytes

Preadipocytes (a) developed into adipocytes (b) after treated with 3T3-L1 differetiation and maturation medium. Arrow shows the lipid droplet stained by oil red O (ORO)

\subsection{Maximum non-toxic dose (MNTD)}

The MNTD was determined to rule out a direct cytotoxic effect of methanol or water extract of F. deltoidea on 3T3-L1 preadipocytes. The MNTD was $(300.0 \pm 28.3) \mu \mathrm{g} / \mathrm{ml}$ for methanol extract (Fig. 2a) and $(225.0 \pm 21.2) \mu \mathrm{g} / \mathrm{ml}$ for water extract (Fig. 2b) of $F$. deltoidea var. deltoidea. Thus, the $1 / 2$ MNTD was $(150.0 \pm 14.1) \mu \mathrm{g} / \mathrm{ml}$ for methanol extract and $(112.5 \pm 10.6) \mu \mathrm{g} / \mathrm{ml}$ for water extract. Water extract at $250.0 \mu \mathrm{g} / \mathrm{ml}$ showed $5.74 \%$ cytotoxicity. In contrast, for methanol extract at $250.0 \mu \mathrm{g} / \mathrm{ml}$ did not show any cytotoxicity against $3 \mathrm{~T} 3-\mathrm{L} 1$ cells.

The MNTD of water extract of $F$. deltoidea var. angustifolia was $(8.0 \pm 1.0) \mu \mathrm{g} / \mathrm{ml}$ (Fig. 3a), while the MNTD of was methanol extract $(60.0 \pm 2.0) \mu \mathrm{g} / \mathrm{ml}$ (Fig. 3b). The MNTDs of these two extracts revealed that water extracts of both $F$. deltoidea varieties had higher cytotoxicity to 3T3-L1 preadipocytes than methanol extracts. This could be due to the presence of high amounts of phenolic compounds, as reflected in the TPC. Phenolic compounds are converted to phenoxyl radicals via oxidative processes in plants, and these radicals are documented to exhibit cytotoxic pro-oxidant activity (Koo and Suhaila, 2001). Also, various indicators of oxidative stress increased following diet supplementation of Helicoverpa zea larvae with phenolic acids (Koo and Suhaila, 2001). In contrast, it has been shown that flavonoids have anti-oxidant, anti-inflammation, and anti-allergic effects (Yasuko et al., 2002). Flavonoids also induce detoxifying enzyme systems such as glutathione $S$-transferase (Yasuko et al., 2002). Moreover, Yasuko et al. (2002) documented that quercetin is involved in inhibiting oxidation and cytotoxicity of low-density lipoprotein in vitro.

\subsection{Determination of anti-adipogenic activity}

The effects of $F$. deltoidea extracts on adipogenesis of 3T3-L1 preadipocytes were determined by treating two-day post-confluent cells with the MNTD or $1 / 2$ MNTD of methanol and water extracts. The addition of methanol extracts of $F$. deltoidea var. deltoidea at both the MNTD and the $1 / 2$ MNTD significantly inhibited adipogenesis of 3T3-L1 preadipocytes (Fig. 4a). In contrast, cells treated with the MNTD and $1 / 2$ MNTD of water extracts of $F$. deltoidea var. deltoidea showed no sign of inhibition compared to the mature adipocytes. 


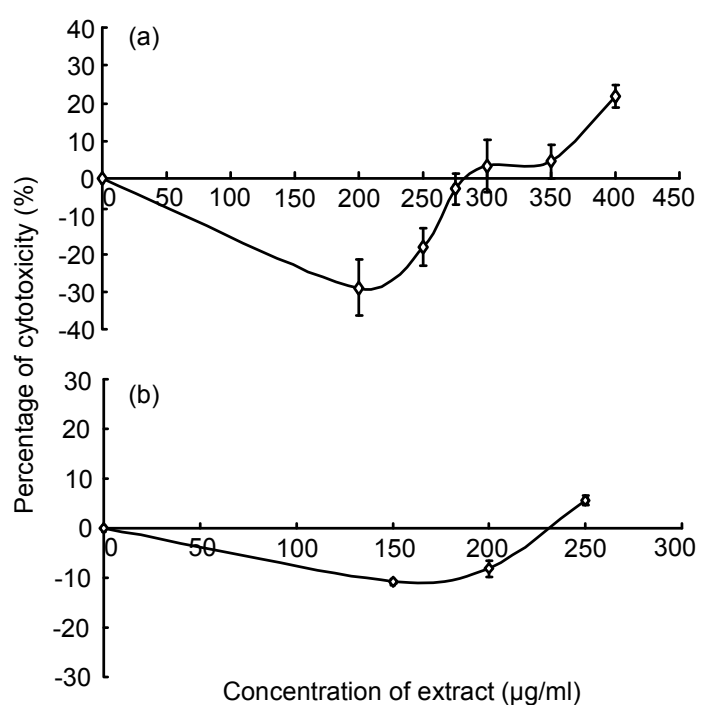

Fig. 2 Percentages of cytotoxicity of methanol extract (a) and water extract (b) of $F$. deltoidea var. deltoidea on 3T3-L1 preadipocytes after incubated for $48 \mathrm{~h}$ in vitro Data are shown as mean $\pm \mathrm{SD}$ of two independent experiments performed in triplicates

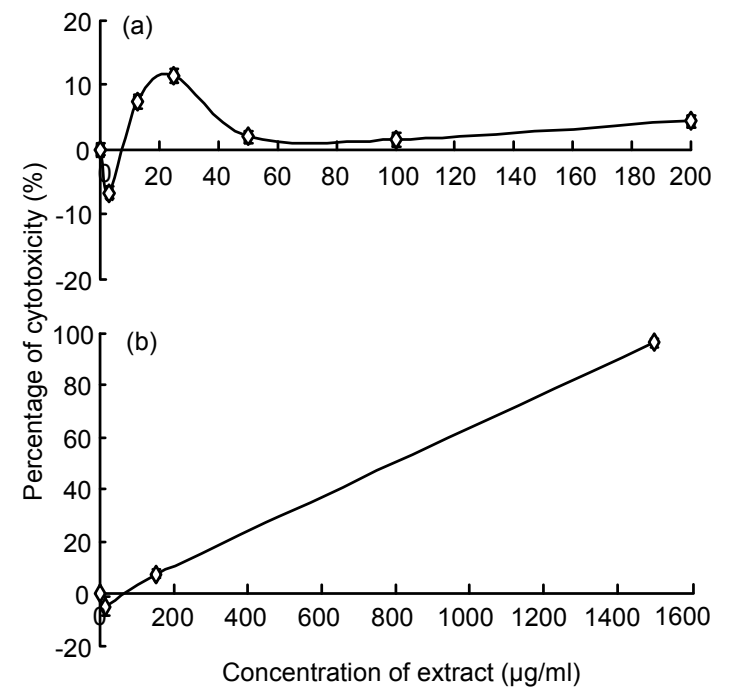

Fig. 3 Percentages of cytotoxicity of water extract (a) and methanol extract (b) of $F$. deltoidea var. angustifolia on 3T3-L1 preadipocytes after treated for $48 \mathrm{~h}$ in vitro Data are shown as mean \pm SD of two independent experiments performed in triplicates

As for $F$. deltoidea var. angustifolia, the untreated 3T3-L1 preadipocytes showed an optical density (OD) value of $0.121 \pm 0.003$, while the untreated mature adipocytes recorded an OD value of $0.281 \pm 0.018$. The ODs for the $1 / 2$ MNTD and MNTD of water extracts were $0.132 \pm 0.009$ and $0.112 \pm 0.006$, respectively, which were significantly different from those of untreated mature adipocytes, as analysed by Tukey's HSD. Although mature adipocytes treated with water extracts showed a lower OD than those treated with methanol extracts, the value recorded was significantly different from that of untreated cells (Fig. 4b). A lower OD reading indicated that the differentiation of 3T3-L1 preadipocytes into mature adipocytes was inhibited. Thus, we concluded that water extracts of $F$. deltoidea var. angustifolia were more potent than methanol extracts in inhibiting adipogenesis of 3T3-L1 preadipocytes.

Adipogenesis is the process of differentiation of preadipocytes into mature adipocytes. When 3T3-L1 preadipocytes are treated with MDI, they are induced to differentiate (Gregoire, 2001). The cells undergo a series of processes, which include alteration of cell shape, growth arrest, and clonal expansion, attributed to the sequence of changes in gene expression and the storage of lipids (Gregoire, 2001). Exogenous glucose uptake and the formation of fatty acids are needed for the accumulation of intracellular lipid droplets in adipocytes (Madsen et al., 2003; Takenouchia et al., 2004). Adipogenesis is a highly regulated process which requires coordinated expression and activation of several transcription factors (Wolfram et al., 2006; Choi et al., 2006). These include peroxisome proliferator activated receptor gamma 2 (PPAR 2 ), CCAAT/enhancer binding protein beta $(\mathrm{C} / \mathrm{EBP} \beta)$, CCAAT/enhancer binding protein delta $(\mathrm{C} / \mathrm{EBP} \delta)$, and CCAAT/enhancer binding protein alpha (C/EBP $\alpha$ ) (Filippini et al., 2010; Sukrasno et al., 2011). The addition of 1-methyl-3-isobutylxanthine and dexamethasone will induce $\mathrm{C} / \mathrm{EBP} \beta$ and $\mathrm{C} / \mathrm{EBP} \delta$, which eventually initiate adipocyte differentiation (Wolfram et al., 2006). This is followed by the induction of PPAR 2 , a key regulator for adipogenesis, and also C/EBP $\alpha$ (Wolfram et al., 2006). PPAR $\gamma 2$ and $\mathrm{C} / \mathrm{EBP} \alpha$ then act together to activate expression of adipose-specific genes to promote adipogenesis (Wolfram et al., 2006).

Processes occurring during the first two to four days after stimulation with adipogenic inducers are vital for adipogenesis (Madsen et al., 2003). Moreover, during this period, PPAR $\gamma$ ligands are needed and adipogenesis is dependent on lipoxygenase activity (Madsen et al., 2003). Thus, adipocyte differentiation 

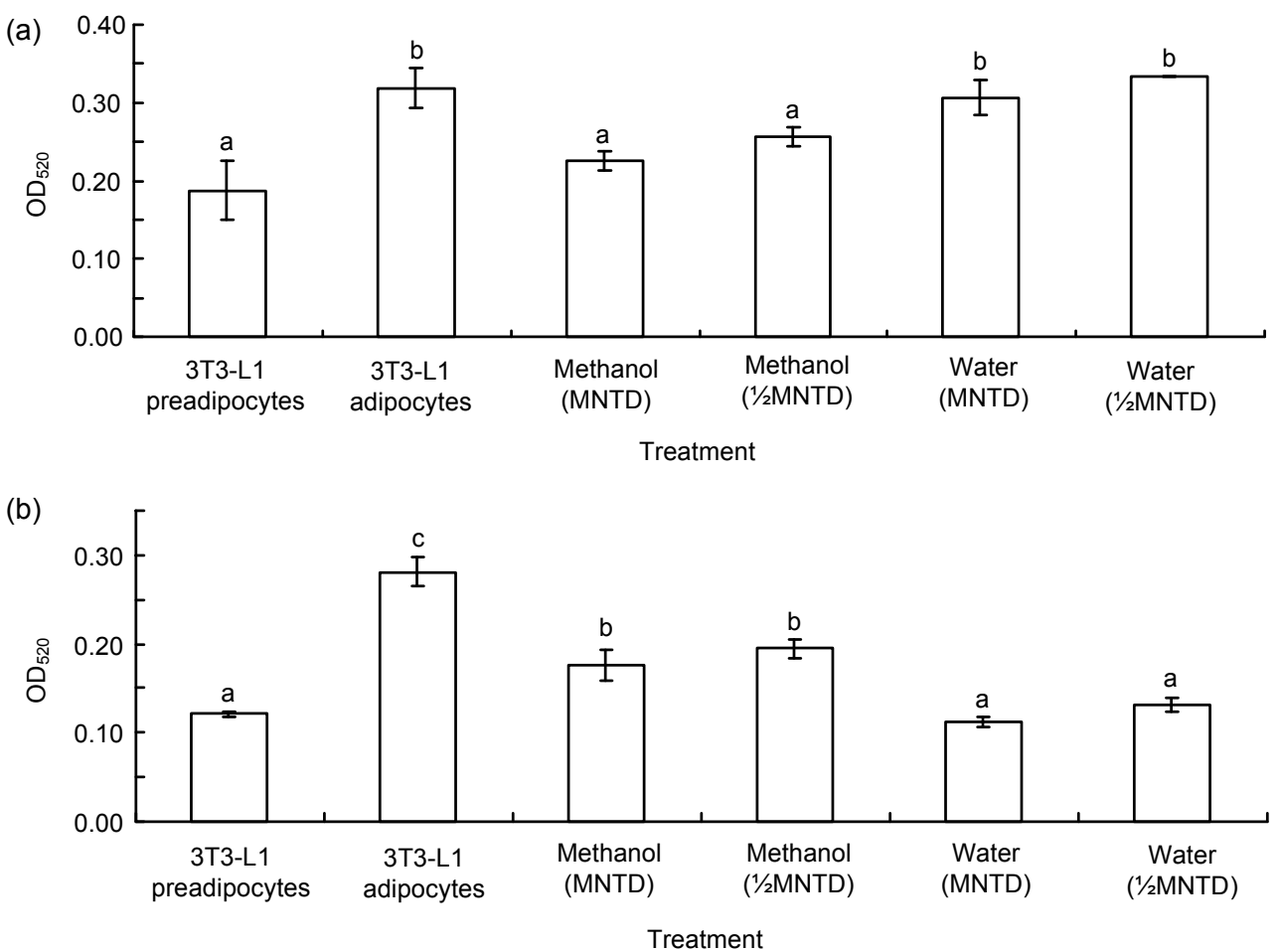

Fig. 4 Adipogenesis assay of extracts of $F$. deltoidea var. deltoidea (a) and var. angustifolia (b) The treated 3T3-L1 mature adipocytes were stained with oil red $\mathrm{O}$ and the dye was extracted. The absorbance of extracted dye was measured at $520 \mathrm{~nm}\left(\mathrm{OD}_{520}\right)$. Data are shown as mean $\pm \mathrm{SD}$ of two independent experiments performed in triplicates. Means with different letters indicate significant differences at $P<0.05$

may have been inhibited by methanol extracts of both varieties, and the water extracts of $F$. deloidea var. angustifolia. Several studies reported that some flavonoids and phenolic compounds are able to inhibit adipogenesis of 3T3-L1 preadipocytes by inhibiting mitotic clonal expansion, triglyceride accumulation, and PPAR $\gamma$ expression (Harmon and Harp, 2001; Choi et al., 2006; Yang et al., 2006; 2007). Quercetin, a flavonoid, has been shown to be involved in preventing insulin receptor tyrosine kinase from phosphorylating substrate, hence blocking insulinmediated lipogenesis (Harmon and Harp, 2001). Also, in an in vitro study of 15 phenolic acids and 6 flavonoids, gallic acid and quercetin were reported to cause the highest inhibition of the growth of 3T3-L1 preadipocytes (Hsu and Yen, 2007) via down-regulation of adipogenic transcription factors such as PPAR $\gamma$ (Harmon and Harp, 2001; Choi et al., 2006; Hsu et al., 2006; Hsu and Yen, 2006; 2007). Gallic acid and quercetin were reported to be present in $F$. deltoidea (Sirisha et al., 2010). It has also been reported that flavonoids and other phenolic compounds found in plants are inhibitors of lipoxygenase (Laughton et al., 1991; Rice-Evans et al., 1996). Therefore, it is possible that flavonoid compounds found in $F$. deltoidea might have influenced early differentiation by inhibiting lipoxygenase activity.

\section{Conclusions}

This study demonstrated that methanol extracts of $F$. deltoidea var. deltoidea showed more significant anti-adipogenic effects on 3T3-L1 adipocytes, compared to water extracts. In contrast, both methanol and water extracts of $F$. deltoidea var. angustifolia may have anti-obesity properties. Nevertheless, more extensive studies should be conducted prior to the development of novel treatments for obesity from $F$. deltoidea extracts. The potential anti-adipogenic compounds present in the extracts should be isolated, purified, and further examined. The mechanisms of action of these potential active compounds should also be determined. 


\section{Compliance with ethics guidelines}

Shiau Mei WOON, Yew Wei SENG, Anna Pick Kiong LING, Soi Moi CHYE, and Rhun Yian KOH declare that they have no conflict of interest.

This article does not contain any studies with human or animal subjects performed by any of the authors.

\section{References}

Abdullah, M.A., Ahmed, K.A.A., Abuluhoom, F.M., et al., 2010. Role of Ficus deltoidea extract in the enhancement of wound healing in experimental rats. Biomed. Res., 21(3):241-245.

Abdullah, N.A.H., Karsani, S.A., Aminudin, N., 2008. Effects of Ficus deltoidea extract on the serum protein profile of simultaneously hypertensive rats. J. Prot. Bioinf., S2:143. [doi:10.4172/jpb.s1000111]

Abdullah, Z., Hussain, K., Zhari, I., et al., 2011. Evaluation of extracts of leaf of three Ficus deltoidea varieties for antioxidant activities and secondary metabolites. Pharmacognosy Res., 1(4):216-223.

Adam, Z., Ismail, A., Khamis, S., et al., 2011. Antihyperglycemic activity of $F$. deltoidea ethanolic extract in normal rats. Sains Malays., 40(5):489-495.

Ahn, J., Lee, H., Kim, S., et al., 2008. The anti-obesity effect of quercetin is mediated by the AMPK and MAPK signaling pathways. Biochem. Biophys. Res. Commun., 373(4):545-549. [doi:10.1016/j.bbrc.2008.06.077]

Aris, S.R.S., Mustafa, S., Ahmat, N., et al., 2009. Phenolic content and antioxidant activity of fruits of Ficus deltoidea var angustifolia sp. Malays. J. Anal. Sci., 13(2): 146-150.

Chang, C.C., Yang, M.H., Wen, H.M., et al., 2002. Estimation of total flavonoid content in propolis of two complementary colorimetric methods. J. Food Drug Anal., 10(3): 178-182.

Choi, I.W., Park, Y.K., Choi, H.D., et al., 2006. Antiadipogenic activity of rutin in 3T3-L1 cells and mice fed with high-fat diet. BioFactors, 26(4):273-281.

Filippini, R., Piovan, A., Borsarini, A., et al., 2010. Study of dynamic accumulation of secondary metabolites in three subspecies of Hypericum perforatum. Fitoterapia, 81(2): 115-119. [doi:10.1016/j.fitote.2009.08.002]

Gregoire, F.M., 2001. Adipocyte differentiation: from fibroblast to endocrine cell. Exp. Biol. Med., 226(11):997-1002.

Guigui, K., Beaudoin, A., 2007. The use of oil red O in sequence with other methods of fingerprint development. $J$. Forensic Identif., 57(4):550-581.

Harmon, A.W., Harp, J.B., 2001. Differential effects of flavonoids on 3T3-L1 adipogenesis and lipolysis. Am. J. Physiol. Cell Physiol., 280(4):C807-C813.

Hsu, C.L., Yen, G.C., 2006. Induction of cell apoptosis in 3T3-L1 preadipocytes by flavonoids is associated with their antioxidant activity. Mol. Nutr. Food Res., 50(11): 1072-1079. [doi:10.1002/mnfr.200600040]

Hsu, C.L., Yen, G.C., 2007. Effects of flavonoids and phenolic acids on the inhibition of adipogenesis in 3T3-L1 adipo- cytes. J. Agric. Food Chem., 55(21):8404-8410. [doi:10. $1021 /$ jf071695r]

Hsu, C.L., Huang, S.L., Yen, G.C., 2006. Inhibitory effect of phenolic acids on proliferation of 3T3-L1 preadipocytes in relation to their antioxidant activity. J. Agric. Food Chem., 54(12):4191-4197. [doi:10.1021/jf0609882]

Ilyanie, Y., Wong, T.W., Choo, C.Y., 2010. Evaluation of hypoglycemic activity and toxicity profiles of the leaves of Ficus deltoidea in rodents. J. Complem. Integr. Med., 8(1):Feb 2011. [doi:10.2202/1553-3840.1469]

Koo, H.M., Suhaila, M., 2001. Flavonoid (myricetin, quercetin, kaempferol, luteolin, and apigenin) content of edible tropical plants. J. Agric. Food Chem., 49(6):3106-3112. [doi:10.1021/jf000892m]

Laughton, M.J., Evans, P.J., Moroney, M.A., et al., 1991. Inhibition of mammalian 5-lipoxygenase and cyclooxygenase by flavonoids and phenolic dietary additives: relationship to antioxidant activity and to iron ionreducing ability. Biochem. Pharmacol., 42(9):1673-1681. [doi:10.1016/0006-2952(91)90501-U]

Lin, J.Y., Tang, C.Y., 2007. Determination of total phenolic and flavonoid contents in selected fruits and vegetables, as well as their stimulatory effects on mouse splenocyte proliferation. Food Chem., 101(1):140-147. [doi:10.1016/ j.foodchem.2006.01.014]

Madsen, L., Petersen, R.K., Sorensen, M.B., et al., 2003. Adipocyte differentiation of 3T3-L1 preadipocytes is dependent on lipoxygenase activity during the initial stages of the differentiation process. Biochem. J., 375: 539-549. [doi:10.1042/BJ20030503]

Moon, H.S., Chung, C.S., Lee, H.G., et al., 2007. Inhibitory effect of (-)-epigallocatechin-3-gallate on lipid accumulation of 3T3-L1 cells. Obesity, 15(11):2571-2582. [doi:10.1038/oby.2007.309]

Ong, S.L., Ling, A.P.K., Poospooragi, R., et al., 2010. Production of flavonoid compounds in cell cultures of Ficus deltoidea as influenced by medium composition. Int. J. Med. Aromatic Plants, 1(2):62-74.

Padwal, M.D., Majumdar, M.D., 2007. Drug treatments for obesity: orlistat, sibutramine, and rimonabant. Lancet, 369(9555):71-77. [doi:10.1016/S0140-6736(07)60033-6]

Preuss, H.G., DiFerdinando, D., Bagchi, M., et al., 2002. Citrus aurantium as a thermogenic, weight-reduction replacement for ephedra: an overview. J. Med., 33(1-4): 247-264.

Rice-Evans, C.A., Miller, N.J., Paganga, G., 1996. Structureantioxidant activity relationships of flavonoids and phenolic acids. Free Radic. Biol. Med., 20(7):933-956. [doi:10.1016/0891-5849(95)02227-9]

Sirisha, N., Sreenivasulu, M., Sangeeta, K., et al., 2010. Antioxidant properties of Ficus species-a review. Int. J. PharmTech Res., 2(4):2174-2182.

Sukrasno, S., Irda, F., Kusnandar, A., et al., 2011. Influence of drying method on flavonoid content of Cosmos caudatus (Kunth) leaves. Res. J. Med. Plant, 5(2):189-195. [doi:10. 3923/rjmp.2011.189.195] 
Sulaiman, M.R., Hussain, M.K., Zakaria, Z.A., et al., 2008. Evaluation of the antinociceptive activity of Ficus deltoidea aqueous extract. Fitoterapia, 79(7-8):557-561. [doi:10.1016/j.fitote.2008.06.005]

Takenouchia, T., Takayamac, Y., Takezawaa, T., 2004. Cotreatment with dexamethasone and octanoate induces adipogenesis in 3T3-L1 cells. Cell Biol. Int., 28(3): 209-216. [doi:10.1016/j.cellbi.2003.11.020]

Wolfram, S., Wang, Y., Thielecke, F., 2006. Anti-obesity effects of green tea: from bedside to bench. Mol. Nutr. Food Res., 50(2):176-187. [doi:10.1002/mnfr.2005 00102]

Yang, J.Y., Della-Fera, M.A., Diane, L.H., et al., 2006. Esculetin induces apoptosis and inhibits adipogenesis in 3T3-L1 cells. Obesity, 14(10):1691-1699. [doi:10.1038/ oby.2006.194]
Yang, J.Y., Della-Fera, M.A., Rayalam, S., et al., 2007. Effect of xanthohumol and isoxanthohumol on 3T3-L1 cell apoptosis and adipogenesis. Apoptosis, 12(11):1953-1963. [doi:10.1007/s10495-007-0130-4]

Yasuko, S., Michael, F.C., Stephen, C.G., et al., 2002. Plant phenolic antioxidant and prooxidant activities: phenolicsinduced oxidative damage mediated by metals in plants. Toxicology, 177(1):67-80. [doi:10.1016/S0300-483X(02) 00196-8]

Zahra, S.F., Mahmood, A.A., Hapipah, M.A., et al., 2009. Anti-ulcerogenic activity of aqueous extract of Ficus deltoidea against ethanol-induced gastric mucosal injury in rats. Res. J. Med. Sci., 3(2):42-46.

\section{中文概要:}

\section{本文题目：金钱榕提取物抑制 3T3-L1 脂肪细胞抗脂肪沉积研究}

Anti-adipogenic effects of extracts of Ficus deltoidea var. deltoidea and var. angustifolia on 3T3-L1 adipocytes

研究目的：对两个品种金钱榕（var. deltoidea 和 var. angustifolia）叶片提取物抑制 3T3-L1 脂肪细胞脂肪 沉积进行研究, 为基于金钱榕的抗肥胖功能产品开发提供理论基础。

研究方法：用甲醇和水分别对两个品种金钱榕的叶片进行提取, 并分别分析了提取物中的总黄酮含量 (TFC) 和总酚含量（TPC）。通过 MTT 法确定提取物对 3T3-L1 脂肪细胞的最大无毒剂量 （MNTD）。然后, 通过油红 $\mathrm{O}$ 染色和吸光度测定来定性和定量研究提取物对抗脂肪细胞脂 肪沉积的作用。

重要结论: 金钱榕两个品种 deltoidea 和 angustifolia 的甲醇提取物中的 TFC 含量分别为 1.36 和 $1.97 \mathrm{~g}$ $\mathrm{QE} / 100 \mathrm{~g} \mathrm{DW}$, 水提取物中的 TPC 含量分别为 5.61 和 $2.73 \mathrm{~g} \mathrm{GAE} / 100 \mathrm{~g} \mathrm{DW}$ 。金钱榕 deltoidea

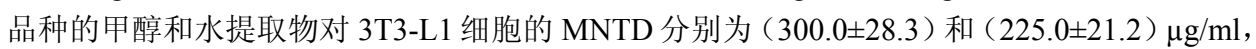
而 angustifolia 品种的 MNTDs 则较低 (其甲醇和水提取物的 MNTDs 分别为 (60.0 2 2.0) 和 $(8.0 \pm 1.0) \mu \mathrm{g} / \mathrm{ml}$ ) 。金钱榕两个品种的甲醇提取物和 angustifolia 品种的水提取物在 MNTD 或 $1 / 2$ MNTD 的浓度下, 均具有显著抑制前脂肪细胞的成熟的作用。因此, 根据其抑制成熟脂 肪细胞形成的结果可以得出金钱榕叶片提取物具有潜在的抗肥胖效果。

关键词组: 脂肪细胞; 金钱榕; 黄酮类化合物; 天然产物; 肥胖 